Article

\title{
Reproducibility and Validity of a Short Food Frequency Questionnaire for Dietary Assessment in Children Aged 7-9 Years in Spain
}

\author{
Jesus Vioque ${ }^{1,2,3,+} \mathbb{D}$, Manuela Garcia-de-la-Hera ${ }^{1,2,3, *} \mathbb{D}$, Sandra Gonzalez-Palacios ${ }^{1,2}$, \\ Laura Torres-Collado ${ }^{1,2}\left(\mathbb{D}\right.$, Leyre Notario-Barandiaran ${ }^{1,2}$, Alejandro Oncina-Canovas ${ }^{1,2}$, \\ Raquel Soler-Blasco ${ }^{4}\left(\mathbb{D}\right.$, Manuel Lozano ${ }^{5}\left(\mathbb{D}\right.$, Andrea Beneito ${ }^{4}(\mathbb{D})$ and \\ Eva-Maria Navarrete-Muñoz ${ }^{1,2,3,6,+(\mathbb{D})}$ \\ 1 Unit of Nutritional Epidemiology, Department of Public Health, History of Medicine and Gynecology, \\ University Miguel Hernández, 03550 Alacant, Spain; vioque@umh.es (J.V.); \\ sandra.gonzalezp@umh.es (S.G.-P.); 1.torres@umh.es (L.T.-C.); lnotario@umh.es (L.N.-B.); \\ aoncina@umh.es (A.O.-C.); enavarrete@umh.es (E.-M.N.-M.) \\ Alicante Institute for Health and Biomedical Research (ISABIAL-FISABIO Foundation), 03010 Alicante, Spain \\ CIBER de Epidemiología y Salud Pública (CIBERESP), Instituto de Salud Carlos III, 28009 Madrid, Spain \\ 4 Epidemiology and Environmental Health Joint Research Unit, FISABIO-Universitat Jaume I-Universitat de \\ València, 46010 Valencia, Spain; Raquel.soler@uv.es (R.S.-B.); Beneito_and@gva.es (A.B.) \\ 5 Foundation for the Promotion of Health and Biomedical Research in the Valencian Region, \\ FISABIO-Public Health, 46035 Valencia, Spain; Lozano_manrel@gva.es \\ 6 Department of Surgery and Pathology, University Miguel Hernández, 03550 Alacant, Spain \\ * Correspondence: manoli@umh.es; Tel.: +34-6-591-9505; Fax: +34-6-591-9551 \\ + These authors contributed equally to this work.
}

Received: 22 March 2019; Accepted: 23 April 2019; Published: 25 April 2019

\begin{abstract}
The purpose of this study was to examine if the short semi-quantitative food frequency questionnaire (FFQ) is a reliable and valid tool to assess the diet of Spanish children aged 7-9 years. We collected data from 156 children of the birth cohort INMA (Infancia y Medio Ambiente (Environment and Childhood)). Children's parents or care-givers completed a 46-item FFQ on two occasions over a 9-12-month period about the children's diet. To explore the reproducibility of the FFQ, the nutrient and food group intake collected from the both FFQs were compared, while validity was examined by contrasting the nutrient values from the FFQs and the average of three 24-hour dietary recalls (24hDRs) taken in this period, and also with the concentration of several vitamins in the blood (carotenoids, vitamin D and $\alpha$-tocopherol). Pearson and de-attenuated correlation coefficients were calculated. The average correlation coefficients for nutrient intake's reproducibility was 0.41 , ranging from 0.25 (calcium) to 0.65 ( $\beta$-carotene), and for food group intake was 0.45 , ranging from 0.18 (cereals) to 0.68 (sweetened beverages). Correlation coefficients slightly improved when we compared energy-adjusted intakes. The average correlation coefficients for validity against $24 \mathrm{hDRs}$ was 0.34 for energy-adjusted intakes, and 0.39 when de-attenuation coefficients were used. The validity coefficients against the blood concentrations of vitamins were 0.38 for $\beta$-cryptoxanthin, 0.26 for lycopene, 0,23 for $\alpha$-carotene and 0.15 for $\beta$-carotene, all of them statistically significant $(p<0.05)$. This study suggests that our brief FFQ is a suitable tool for the dietary assessment of a wide range of nutrients and food groups in children 7-9 years, despite the low to moderate reproducibility and validity observed for some nutrients.
\end{abstract}

Keywords: diet; nutrient intake; food frequency questionnaire; childhood; validity; 24-hour dietary recall; nutritional biomarker; reproducibility; Mediterranean country 


\section{Introduction}

Diet in childhood plays vital role on the risk of chronic processes such as obesity, type II diabetes, hypertension, and cardiovascular diseases in adult life [1,2]. Thus, an accurate assessment of the child dietary intake is crucial to monitor nutritional status, its relationship with other lifestyles, and to elucidate the consequences on health and disease later in life.

In assessing a complex exposure like long-term dietary intake in epidemiological studies, food frequency questionnaires (FFQs) have been suggested as the best option because this tool saves time and money compared to other dietary methods [3]. At present, many FFQs have been developed and validated in different populations around the world, mostly in adult populations [4-6] and, to a lesser extent, in other specific populations such as pregnant women [7], children or infants [8,9], adolescents [10,11] or elderly people [12].

To date, few validation studies of FFQs have been published for children aged 6-12 years, of which 11 studies were summarized in a systematic review conducted by Orti-Andrelluchi in 2009 [9] and 14 studies were developed in more recent years [13-22]. Briefly, these studies were conducted in Europe $(n=7)$, South-America $(n=6)$, Australia $(n=5)$, United States $(n=3)$, Canada $(n=2)$, and Asia $(n=3)$; the majority of FFQs were used to assess macro and micro nutrients, and the length of FFQs encompasses a range between 50 and 160 items. The food records and dietary recalls were the preferred dietary assessment methods used as the reference for comparison with FFQs; and average correlation coefficients between nutrient intake in the validation studies was low-moderate (0.3-0.5).

In Spain, there is no validated FFQs to assess dietary intake of school-aged children (6-12 years). Therefore, the purpose of the present study was to examine if the short semi-quantitative FFQ is reliable and valid against three 24-hour dietary recalls (24hDRs) and several vitamins in blood (carotenoids, vitamin $\mathrm{D}$ and $\alpha$-tocopherol) tool to assess the diet in Spanish children aged 7-9 years.

\section{Materials and Methods}

\subsection{Study Population}

Participants involved in this validation study were 156 healthy children aged 7-9 years from the Spanish multicenter population-based birth cohort study, the INMA (Infancia y Medio Ambiente (Environment and Childhood)) Project [23]. The present study was conducted in participants from the INMA cohort in Valencia. Briefly, 787 pregnant women delivered a live infant between May 2004 and February 2006, and 461 children attended a planned follow-up visit at the age of 7-9 years. The final sample was estimated to guarantee statistical significance for correlation coefficients of $r \geq 0.20$ [3]. The design of the validation study is shown in Figure 1. Following standardized procedures, the participants completed with trained nutritionist two FFQs and three 24 hours' dietary recalls (24hDRs) in a period of 6-12 months and provided a blood sample at baseline. The majority of the children of this study had been also involved in a previous FFQ validation study at $4-5$ years old [24]. The research protocol of the study was approved for the ethics committees of the centers involved in the study and the parents of children provided informed consent. 


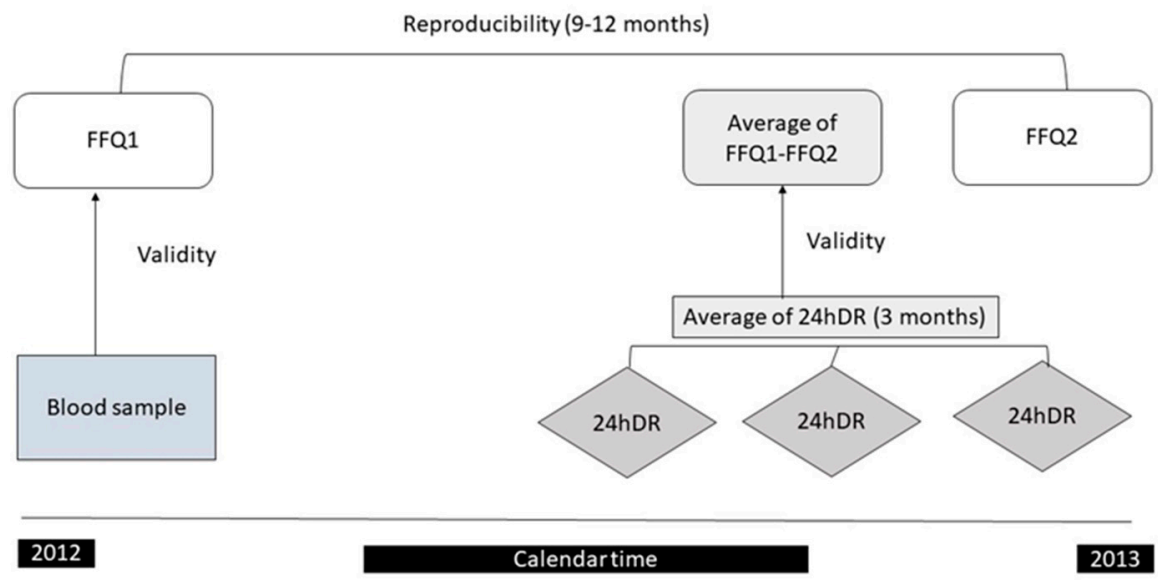

Figure 1. The desing of the validation study among children aged 7 to 9 years of the INMA (Infancia y Medio Ambiente (Environment and Childhood)) project in Valencia, 2012-2013. FFQ: food frequency questionnaire; 24hDR: 24-hour dietary recall.

\subsection{Dietary Assessment: Semi-Quantitative Food Frequency Questionnaire (FFQ)}

Child dietary usual intake was retrospectively assessed by trained nutritionists at the 7-9-year follow-up visit using a short semi-quantitative FFQ of 46 food items (available at: http://epinut.edu. umh.es/cfa-46-items/). The FFQ is based on the Harvard questionnaire structure [25] and was derived from previous Spanish FFQs designed to evaluate the dietary intake in pregnancy of the mothers from the INMA-Valencia cohort, and the dietary intake of their children at the age of 4-5 years, showing a good reproducibility and moderate validity $[24,26]$. The new FFQ was adapted to include food items and portion sizes appropriated for children aged 7 to 9 years and to reduce the number of the items. Parents were asked to report the average frequency of consumption of their children for each item on the FFQ in reference to the past 9-12 months. The questionnaire has nine possible answers, from "never once or less than once a month" to "six or more times a day". The US Department of Agriculture food composition tables and other Spanish published sources $[27,28]$ were used to estimate nutrient values and total energy intake. In order to obtain average daily nutrient intakes from diet for each child, we multiplied the frequency of consumption of each item by the nutrient content of the portion specified in the FFQ and added the results across all foods. The supplement use was not taken into account to estimate nutrient intake due to a low percentage of children took supplements in our study. We also estimated the mean daily intake of 17 food groups (Table 1).

\subsection{4-Hour Dietary Recall (24hDR)}

Three non-consecutive 24hDRs, including at least one non-weekday, were collected by trained nutritionists using the United States Department of Agriculture (USDA) Automated Multiple-Pass Method to minimize the forgotten food and beverages consumed, and increase the quality of the dietary information collected [29]. The three $24 \mathrm{hDRs}$ were completed during 3-month period by telephone interview; and the third 24hDR was filled out at the same time as the second FFQ. The nutritionist collected the portions, method of preparation and brands to estimate the intake from $24 \mathrm{hDRs}$ using the Food Processor Nutrition Analysis Software. The USDA food composition tables and other Spanish published sources $[27,28]$ were used to estimate the nutrient and total energy intake. We used the average of three $24 \mathrm{hDRs}$ as a representation of individual intakes. 
Table 1. Description of the food items included in the food groups.

\begin{tabular}{|c|c|}
\hline $\begin{array}{l}\text { Food Groups (Number of } \\
\text { Foods Items) }\end{array}$ & Foods \\
\hline Dairy Products (4) & whole dairy products; semi-skimmed, skimmed and fortified dairy products; Petit Suisse; cheese. \\
\hline Eggs (1) & Eggs \\
\hline White meat (1) & chicken or turkey \\
\hline Red meat (1) & beef, pork or lamb \\
\hline Processed meat (3) & sausages; ham, salami and others; serrano ham \\
\hline Fatty fish (3) & $\begin{array}{l}\text { swordfish, bonito, and fresh tuna; small oily fish (mackerel, sardine; anchovy); canned sardine } \\
\text { or mackerel }\end{array}$ \\
\hline Lean fish (1) & A assorted or mixed fried fish (hake; gilthead sea bream and sole) \\
\hline Seafood (2) & $\begin{array}{l}\text { clams, mussels, squid, octopus, shellfish (cramps, shrimps, lobster); surimi and other fish-based } \\
\text { food products }\end{array}$ \\
\hline Fruits (2) & oranges; other fruit (apples; banana; pears; watermelon; melon; peach; kiwi; cherries, strawberries) \\
\hline Vegetables (2) & $\begin{array}{l}\text { raw vegetables (tomatoes; onions; lettuces; peppers and carrots) and cooked vegetables (spinach; } \\
\text { cabbage, cauliflower or broccoli; carrots or squash; eggplant, zucchini, or cucumber; green, red, } \\
\text { or yellow peppers) }\end{array}$ \\
\hline Nuts (1) & almonds, walnuts, peanuts and other types of nuts \\
\hline Legumes (1) & lentils, chickpeas, beans, peas, and green beans \\
\hline Cereals and Pasta (2) & breakfast cereals; corn, rice and pasta \\
\hline Bread (2) & white and whole breads \\
\hline Potatoes (2) & frozen French fry; homemade boiled/stew \\
\hline Sweets and sugar (5) & $\begin{array}{l}\text { biscuits and baked goods; biscuits and baked goods with chocolate; peanut butter (e.g., Nutella/Nocilla); } \\
\text { chocolate/cocoa powder; candies, marmalade, and honey }\end{array}$ \\
\hline Sweetened beverages (3) & packages juices; sugar soft drinks and artificially soft drinks \\
\hline
\end{tabular}

\subsection{Nutritional Biomarkers}

All the participants provided a non-fasting blood sample at the baseline interview. Vitamin E, D (25-OH-vitamin D), retinol and carotenoids were determined by the General Biochemistry and Hematology Laboratories of the Hospital Puerta de Hierro, Madrid, according to routine quality-controlled standard methods [24,30,31]. In brief, the whole blood samples were centrifuged at $6000 \mathrm{rpm}$ for five minutes to separate blood cells and serum samples within $30 \mathrm{~min}$ after of collection. Afterwards, the samples were stored at $-80{ }^{\circ} \mathrm{C}$ until they were sent to the central laboratory using the standardized protocol by specialized couriers. Serum carotenoids were measured by high performance liquid chromatography (HPLC) with diode array detection using the method which was described by Craft [32], andserum concentrations of $\alpha$-tocopherol, retinol, vitamin D and individuals carotenoids were simultaneously measured by ultra-fast-liquid chromatography [33]. The short and long-term precision and accuracy of the analytical method of laboratory is verified periodically through participation in the Fat-Soluble Quality Assurance Programme conducted by the National Institute of Standards and Technology (NIST; Gaithersburg, MD, USA). Plasma cholesterol was determined to adjust carotenoid concentrations, and the information of serum lutein and zeaxanthin were combined due to this dietary information is grouped in the composition tables.

\subsection{Statistical Analysis}

R software version 3.4.2 (R Foundation for Statistical Computing, Vienna, Austria; http://www.rproject.org) was used to perform statistical analysis. Statistical test were bilateral and significance was determined at level of 0.05 . To compare characteristics of the children and their mothers participants $(n=156)$ and non-participants $(n=305)$ in the validation study, we calculated the Chi-square test or Fisher's exact for categorical variables and Student's $t$-test for continuous variables.

We described the nutrient and food groups intakes from FFQ, 24hDRs, and biomarkers using meansand standard deviations. To compare the means between different assessment methods, we used paired Student's $t$-test. 
The nutrient and food group intakes were log transformed to reduce skewness and optimize the normality of the dietary intake distribution. Energy-adjusted intakes were computed using the residual method, where each nutrient is regressed on total calories and the population mean was then added back to the calculated residuals [34]. The plasma carotenoids and tocopherol biomarkers were also adjusted for plasma cholesterol concentrations using the residual method due to these nutrients being transported in plasma lipoproteins. To evaluate the reproducibility of the FFQ, we performed Pearson correlations coefficients between nutrient and food intake measured in two occasions (around 9-12 months). The validity of the FFQ was also computed with Pearson correlation coefficients using as reference method the average of three $24 \mathrm{hDRs}$ and biomarkers. To avoid the within-person variation found in the $24 \mathrm{hDRs}$, de-attenuated correlations were calculated using the following formula:

$$
\sqrt{1+\left\{\left(\frac{S 2 w}{S 2 b}\right) / n\right\}}
$$

where $S 2 w$ represents within-person variance and $S 2 b$ between-person variance for each nutrient and $n$ is the number of replicated 24hDRs (in our case $n=3$ ) [25]. Due to similar results of Spearman and Pearson correlations, we decided not to present Spearman correlations. We also calculated the percentage of agreement as the proportions of individuals who were classified correctly into the same or adjacent quintile for reproducibility and validity analyses. But, this percentage was not calculated for the food groups' reproducibility due to the distribution of food group intakes which did not permit us to estimate quintiles.

We examined Bland-Altman plots [35] separately for each of the 31 nutrients to explore the direction of bias across levels of intake and determine the agreement between the two dietary assessment methods used to compare the nutrient intakes (e.g., mean of FFQs vs. average of three 24hDRs).

\section{Results}

The characteristics of the children and mothers of the study population by their participation or non-participation in the validation study are shown in Table 2. Overall, no differences were found between participants or non-participants, except for body mass index (BMI), which was slightly higher in non-participants than in participants (mean 18.0 vs. $17.1 ; p=0.001$ ). Children participating in the validation study were on average 7.6 years old, of which $45.5 \%$ were female and $62.8 \%$ were to the school lunchroom once or more times a week. Regarding maternal characteristics of these children, their mothers had a mean age of 30.0 years, more than a third (31.4\%) had university studies, $22.4 \%$ belonged to a high social class, and $88.5 \%$ were born in Spain. In addition, the energy and macronutrients intake at baseline as measured by the first FFQ was very similar between participants and non-participants. The mean daily energy intake in children participants was $1960 \mathrm{Kcals} /$ day and $87 \mathrm{~g} /$ day for proteins, $245 \mathrm{~g} /$ day for carbohydrates and $75 \mathrm{~g} /$ day for total fat.

\subsection{Reproducibility}

The mean daily nutrient intake, Pearson correlation coefficients and percentage of agreement between the two FFQs completed in approximately a 9-12 month period are presented in Table 3 . No differences in nutrients intakes were observed between two FFQs, except for monounsaturated fatty acids, $\beta$-cryptoxanthin, vitamin $C$ and vitamin $E$ that showed slightly higher mean consumption in the second FFQ. The average correlation coefficient for crude intakes was 0.41 and for energy-adjusted intakes was 0.46 . The correlations for crude intakes ranged from 0.25 for calcium to 0.65 for $\beta$-carotene, and all correlations were higher when we used total energy-adjusted intakes. The percentage of agreement of nutrient intake in both FFQs was in average was $69.2 \%$, ranging from $59.6 \%$ for monounsaturated fatty acids to $81.4 \%$ for $\beta$-carotene. The reproducibility of the FFQ for food groups was on average similar to the nutrients; 0.45 for crude intakes and 0.46 in total energy-adjusted intakes (Table 4). We observed a significantly higher mean intake of eggs and fruit and a lower mean intake of 
dairy in the second FFQ. The lowest reproducibility in crude and total energy-adjusted coefficients were observed for cereal intake ( $r=0.18$ and $r=0.15$, respectively), and the highest for sweetened beverages ( $r=0.68$ in both coefficients).

\subsection{Validity}

Table 5 displays mean daily nutrient intakes, and Pearson correlations coefficients from the average of two FFQs and the average of three 24hDRs. The mean of nutrient intakes estimated using FFQs were higher than those from the 24hDRs, but the lycopene and vitamin B12 intakes for both methods were very similar between the FFQs and 24hDRs. The average of correlation coefficients for the crude intake, energy-adjusted intake and de-attenuation were $0.31,0.34$ and 0.39 , respectively. For crude intakes, the coefficients ranged from $r=0.14$ (iodine) to 0.48 ( $\beta$-cryptoxanthin) whereas the adjustment for energy intake had a similar effect on the levels of correlations. In the comparison of absolute intake assessed by the FFQ and $24 \mathrm{hDR}$, we observed the percentage of agreement was in average of $61.4 \%$, encompassing a range from $51.9 \%$ (protein) to $71.2 \%$ (retinol).

Table 2. Characteristics of children and their mothers who attended a 7-9 year follow up distinguishing between participants or no participants in the validation study (Yes/No) of the INMA-Valencia cohort study.

\begin{tabular}{lccc}
\hline & \multicolumn{2}{c}{ Participation in the Validation Study } & \multirow{2}{*}{$p$-Value ${ }^{\mathbf{1}}$} \\
\cline { 2 - 3 } & Yes $(\boldsymbol{n}=\mathbf{1 5 6})$ & No $(\boldsymbol{n}=\mathbf{3 0 5})$ & \\
\hline Maternal Characteristics & & & \\
Age (years), mean (standard deviation (SD)) & $30.0(4.0)$ & $30.8(4.2)$ & 0.058 \\
$\quad$ Education (University studies), $\%$ & 31.4 & 29.5 & 0.645 \\
Social class (I + II; high), $\%$ & 22.4 & 19.7 & 0.469 \\
$\quad$ Country of birth (Spain), $\%$ & 88.5 & 86.2 & 0.560 \\
\hline Child Characteristics & & \\
Age (years), mean (SD) & $7.6(0.1)$ & $7.6(0.2)$ & 0.666 \\
Sex (female), $\%$ & 45.5 & 51.8 & 0.237 \\
Body Mass Index (Kg/m $\left.{ }^{2}\right)$, mean (SD) & $17.1(2.7)$ & $18.0(3.0)$ & 0.001 \\
School lunchroom ( $\geq 1$ time/week), $\%$ & 62.8 & 64.8 & 0.682 \\
Energy (Kcals/day), mean (SD) & $1960(459)$ & $1902(435)$ & 0.188 \\
Proteins (g/day), mean (SD) & $87(18)$ & $85(18)$ & 0.391 \\
Carbohydrates (g/day), mean (SD) & $245(65)$ & $233(62)$ & 0.054 \\
Fats (g/day), mean (SD) & $75(20)$ & $74(19)$ & 0.725 \\
\hline 1 -values from Student's t-test (continuous variables) and from Chi-square or Exact Fisher tests (categorical variables)
\end{tabular}

Table 3. Mean daily nutrient intakes and Pearson correlation coefficients in two FFQs in children aged 7-9 years of the INMA-Valencia study $(n=156)$.

\begin{tabular}{|c|c|c|c|c|c|c|}
\hline \multirow[t]{2}{*}{ Nutrient Intakes (units/day) } & \multirow{2}{*}{$\begin{array}{c}\text { FFQ1 }^{1} \\
\text { Mean (SD) }\end{array}$} & \multirow{2}{*}{$\begin{array}{c}\text { FFQ2 }^{1} \\
\text { Mean (SD) }\end{array}$} & \multirow{2}{*}{$p$-Value ${ }^{2}$} & \multicolumn{2}{|c|}{$\begin{array}{l}\text { Pearson Coefficient Correlations } \\
\text { between FFQ1 and FFQ2 }\end{array}$} & \multirow[t]{2}{*}{$\begin{array}{c}\% \text { of } \\
\text { Agreement }\end{array}$} \\
\hline & & & & $\mathbf{r}^{3}$ & r adj. ${ }^{4}$ & \\
\hline Protein $(g /$ day $)$ & $87(18)$ & $85(17)$ & 0.344 & 0.29 & 0.48 & 62.8 \\
\hline Total carbohydrates (g/day) & $245(65)$ & $243(60)$ & 0.698 & 0.36 & 0.40 & 68.6 \\
\hline Dietary fiber (g/day) & $20.3(6.1)$ & $21.1(6.1)$ & 0.226 & 0.43 & 0.51 & 66.7 \\
\hline SFA (g/ day) & $25.7(7.9)$ & $25.6(7.6)$ & 0.903 & 0.34 & 0.42 & 62.2 \\
\hline MUFA (g/day) & $28.2(8.7)$ & $31.2(9)$ & 0.004 & 0.33 & 0.24 & 59.6 \\
\hline PUFA (g/day) & $12.6(3.7)$ & $13.4(4)$ & 0.101 & 0.42 & 0.49 & 67.9 \\
\hline Omega 3 (g/day) & $1.3(0.4)$ & $1.4(0.4)$ & 0.411 & 0.43 & 0.57 & 67.9 \\
\hline Omega 6 (g/day) & $11.1(3.3)$ & $11.8(3.7)$ & 0.083 & 0.42 & 0.47 & 67.9 \\
\hline Trans fatty acid (g/day) & $1.2(0.4)$ & $1.2(0.4)$ & 0.386 & 0.32 & 0.42 & 75.6 \\
\hline
\end{tabular}


Table 3. Cont.

\begin{tabular}{|c|c|c|c|c|c|c|}
\hline \multirow[t]{2}{*}{ Nutrient Intakes (units/day) } & \multirow{2}{*}{$\begin{array}{c}\text { FFQ1 }^{1} \\
\text { Mean (SD) }\end{array}$} & \multirow{2}{*}{$\begin{array}{c}\text { FFQ2 }^{1} \\
\text { Mean (SD) }\end{array}$} & \multirow[t]{2}{*}{$p$-Value ${ }^{2}$} & \multicolumn{2}{|c|}{$\begin{array}{l}\text { Pearson Coefficient Correlations } \\
\text { between FFQ1 and FFQ2 }\end{array}$} & \multirow[t]{2}{*}{$\begin{array}{c}\% \text { of } \\
\text { Agreement }\end{array}$} \\
\hline & & & & $\mathrm{r}^{3}$ & $\mathrm{radj}^{4}$ & \\
\hline Lutein + Zeaxanthin $(\mu \mathrm{g} /$ day $)$ & $1451(780)$ & $1481(939)$ & 0.758 & 0.54 & 0.55 & 73.7 \\
\hline Lycopene $(\mu \mathrm{g} /$ day $)$ & $2800(1355)$ & $2942(1682)$ & 0.412 & 0.44 & 0.45 & 70.5 \\
\hline Vitamin B6 (mg/day) & $1.7(0.7)$ & $1.7(0.6)$ & 0.962 & 0.47 & 0.49 & 71.2 \\
\hline Vitamin C (mg/day) & $78(41)$ & $95(58)$ & 0.002 & 0.51 & 0.46 & 72.4 \\
\hline Vitamin D ( $\mu \mathrm{g} /$ day $)$ & $4.4(1.6)$ & $4.4(1.5)$ & 0.789 & 0.47 & 0.54 & 69.9 \\
\hline Vitamin E (mg/day) & $7.6(2.3)$ & $8.4(2.6)$ & 0.002 & 0.39 & 0.44 & 63.5 \\
\hline Calcium (mg/day) & $1135(344)$ & $1105(310)$ & 0.429 & 0.25 & 0.35 & 65.4 \\
\hline Iron (mg/day) & $13(5.2)$ & $13(4.5)$ & 0.942 & 0.45 & 0.46 & 72.4 \\
\hline Magnesium (mg/day) & $284(64)$ & $282(64)$ & 0.752 & 0.31 & 0.43 & 64.7 \\
\hline \multicolumn{4}{|l|}{ Average of correlation coefficients } & 0.41 & 0.46 & 69.2 \\
\hline
\end{tabular}

1 FFQ1 \& FFQ2, the same FFQ was firstly administered at baseline (FFQ1) and secondly (FFQ2), between 9 to 12 months later; ${ }^{2} p$-value from paired $t$-tests; ${ }^{3} \mathrm{r}$ : coefficient correlations after nutrient crude intakes were log-transformed; ${ }^{4} \mathrm{r}$ adj: correlation coefficient using nutrient intakes adjusted for total energy; ${ }^{5}$ Percentage of children classified in the same or an adjacent quintile in nutrient crude intakes; SFA, saturated fatty acids; MUFA, monounsaturated fatty acids; PUFA, polyunsaturated fatty acids; all correlation coefficients were statistically significant, $p<0.01$.

Table 4. Mean daily food group intakes and Pearson correlation coefficients in two FFQs among children aged 7-9 years of the INMA-Valencia study $(n=156)$.

\begin{tabular}{|c|c|c|c|c|c|}
\hline \multirow{2}{*}{$\begin{array}{l}\text { Food Groups } \\
\text { (g/day) }\end{array}$} & \multirow{2}{*}{$\begin{array}{c}\text { FFQ1 }^{1} \\
\text { Mean (SD) }\end{array}$} & \multirow{2}{*}{$\begin{array}{c}\text { FFQ2 }^{1} \\
\text { Mean (SD) }\end{array}$} & \multirow{2}{*}{$p$-Value ${ }^{2}$} & \multicolumn{2}{|c|}{$\begin{array}{c}\text { Pearson Coefficient Correlations } \\
\text { between FFQ1 and FFQ2 }\end{array}$} \\
\hline & & & & $r^{3}$ & r adj. 4 \\
\hline Dairy products & $561(244)$ & $505(211)$ & 0.031 & 0.25 & 0.32 \\
\hline Eggs & $22(9)$ & $24(9)$ & 0.046 & 0.59 & 0.57 \\
\hline White meat & 40 (15) & $38(14)$ & 0.497 & 0.42 & 0.42 \\
\hline Red meat & $27(15)$ & $25(15)$ & 0.282 & 0.40 & 0.40 \\
\hline Processed meat & $35(22)$ & $32(14)$ & 0.138 & 0.37 & 0.39 \\
\hline White fish & $24(13)$ & $23(13)$ & 0.560 & 0.58 & 0.57 \\
\hline Blue fish & $16(14)$ & $18(14)$ & 0.288 & 0.61 & 0.63 \\
\hline Seafood & $9(15)$ & $7(9)$ & 0.131 & 0.45 & 0.45 \\
\hline Vegetables & $95(73)$ & $103(82)$ & 0.392 & 0.60 & 0.60 \\
\hline Fruit & $160(107)$ & $218(145)$ & $<0.001$ & 0.67 & 0.65 \\
\hline Nuts & $4(4)$ & $4(4)$ & 0.785 & 0.28 & 0.30 \\
\hline Pulse & $33(21)$ & $31(19)$ & 0.458 & 0.57 & 0.56 \\
\hline Cereals & $82(50)$ & $81(38)$ & 0.846 & 0.18 & 0.15 \\
\hline Potatoes & $40(20)$ & $39(19)$ & 0.628 & 0.34 & 0.32 \\
\hline Bread & $98(51)$ & $99(48)$ & 0.872 & 0.35 & 0.39 \\
\hline Sweet and sugar & $75(52)$ & $68(47)$ & 0.200 & 0.34 & 0.35 \\
\hline Sweetened beverages & $141(153)$ & $137(142)$ & 0.807 & 0.68 & 0.68 \\
\hline \multicolumn{4}{|c|}{ Average of correlation coefficients } & 0.45 & 0.46 \\
\hline
\end{tabular}

${ }^{1}$ FFQ1 and FFQ2, the same FFQ was firstly administered at baseline (FFQ1) and secondly (FFQ2), between 9 to 12 months later. ${ }^{2} p$-value from paired $t$-tests; ${ }^{3} \mathrm{r}$ : coefficient correlations after food groups intakes were log-transformed; ${ }^{4} \mathrm{r}$ adj: correlation coefficient using food groups intakes adjusted for total energy; the correlations coefficients had a $p$-value $<0.01$ when $r \geq 0.20$, and a $p$ value $<0.05$ when $0.15 \leq r \leq 0.19$. 
Table 5. Mean daily nutrient intakes and Pearson correlation coefficients from the average of two FFQs and three $24 \mathrm{hDR}$ among children aged 7-9 years of the INMA-Valencia study $(n=156)$.

\begin{tabular}{|c|c|c|c|c|c|c|c|}
\hline \multirow[t]{2}{*}{ Nutrients (units/day) } & \multirow{2}{*}{$\begin{array}{c}\text { FFQav }^{1} \\
\text { Mean (SD) }\end{array}$} & \multirow{2}{*}{$\begin{array}{l}24 \text { hDRav }^{2} \\
\text { Mean (SD) }\end{array}$} & \multirow[t]{2}{*}{$p$-Value $^{3}$} & \multicolumn{3}{|c|}{$\begin{array}{l}\text { Pearson Coefficient Correlations } \\
\text { between FFQav and 24hDRav }\end{array}$} & \multirow[t]{2}{*}{$\begin{array}{c}\% \text { of } \\
\text { Agreement }\end{array}$} \\
\hline & & & & $r^{4}$ & r adj. 5 & r de-att. ${ }^{6}$ & \\
\hline Energy (kcals/day) & 1957 (354) & $1662(271)$ & $<0.001$ & 0.31 & & & 62.2 \\
\hline Protein (g/day) & $86(14)$ & $70(13)$ & $<0.001$ & 0.25 & 0.36 & 0.42 & 51.9 \\
\hline Total carbohydrates (g/day) & $244(52)$ & $211(43)$ & $<0.001$ & 0.40 & 0.34 & 0.39 & 65.4 \\
\hline Dietary fiber (g/day) & $20.7(5.2)$ & $12.9(3.6)$ & $<0.001$ & 0.32 & 0.29 & 0.30 & 57.1 \\
\hline Cholesterol (g/day) & $285(58)$ & $229(71)$ & $<0.001$ & 0.23 & 0.28 & 0.31 & 58.3 \\
\hline Total fat (g/ day) & $75(16)$ & $62(13)$ & $<0.001$ & 0.24 & 0.32 & 0.34 & 57.7 \\
\hline SFA (g/ day) & $25.6(6.3)$ & $21.9(5.2)$ & $<0.001$ & 0.35 & 0.32 & 0.35 & 60.3 \\
\hline MUFA (g/day) & $29.7(7.2)$ & $24.1(5.8)$ & $<0.001$ & 0.18 & 0.26 & 0.28 & 58.3 \\
\hline PUFA (g/ day) & $13(3.2)$ & $9.8(3.1)$ & $<0.001$ & 0.24 & 0.38 & 0.50 & 58.3 \\
\hline Omega 3 (g/day) & $1.3(0.4)$ & $1(0.3)$ & $<0.001$ & 0.24 & 0.31 & 0.37 & 57.7 \\
\hline Omega 6 (g/day) & $11.5(2.9)$ & $8.7(2.8)$ & $<0.001$ & 0.25 & 0.38 & 0.54 & 63.5 \\
\hline Trans fatty acids (g/day) & $1.2(0.3)$ & $0.5(0.3)$ & $<0.001$ & 0.44 & 0.48 & 0.60 & 67.3 \\
\hline Retinol ( $\mu \mathrm{g} /$ day $)$ & $446(165)$ & $374(205)$ & 0.001 & 0.46 & 0.45 & 0.57 & 71.2 \\
\hline$\alpha$-Carotene ( $\mu \mathrm{g} /$ day $)$ & $862(601)$ & $200(301)$ & $<0.001$ & 0.32 & 0.31 & 0.33 & 61.5 \\
\hline$\beta$-Carotene $(\mu \mathrm{g} /$ day $)$ & 2902 (1899) & $955(944)$ & $<0.001$ & 0.43 & 0.43 & 0.45 & 64.1 \\
\hline$\beta$ - Cryptoxanthin ( $\mu \mathrm{g} /$ day) & $181(102)$ & $94(95)$ & $<0.001$ & 0.48 & 0.48 & 0.54 & 64.7 \\
\hline Lutein + Zeaxanthin $(\mu \mathrm{g} /$ day $)$ & $1466(726)$ & $655(924)$ & $<0.001$ & 0.24 & 0.24 & 0.26 & 57.1 \\
\hline Lycopene ( $\mu \mathrm{g} /$ day) & $2871(1300)$ & $2679(2028)$ & 0.319 & 0.22 & 0.20 & 0.20 & 60.9 \\
\hline Vitamin B6 (mg/day) & $1.7(0.5)$ & $1.4(0.5)$ & $<0.001$ & 0.46 & 0.49 & 0.50 & 68.6 \\
\hline Folate $(\mu \mathrm{g} /$ day $)$ & $218(47)$ & $151(50)$ & $<0.001$ & 0.25 & 0.28 & 0.29 & 60.3 \\
\hline Vitamin B12 ( $\mu \mathrm{g} /$ day) & $6.4(1.8)$ & $5.8(5.7)$ & 0.223 & 0.28 & 0.30 & 0.39 & 64.1 \\
\hline Vitamin C (mg /day) & $87(41)$ & $53(35)$ & $<0.001$ & 0.43 & 0.44 & 0.56 & 64.1 \\
\hline Vitamin D ( $\mu \mathrm{g} /$ day $)$ & $4.4(1.3)$ & $2.7(1.8)$ & $<0.001$ & 0.22 & 0.24 & 0.28 & 59.6 \\
\hline Vitamin E (mg/day) & $8(2)$ & $5.1(1.7)$ & $<0.001$ & 0.19 & 0.23 & 0.26 & 57.7 \\
\hline Calcium (mg/day) & $1120(264)$ & $898(240)$ & $<0.001$ & 0.38 & 0.45 & 0.50 & 59.6 \\
\hline Iron (mg/day) & $13(4.1)$ & $10.7(4.3)$ & $<0.001$ & 0.41 & 0.37 & 0.43 & 66.7 \\
\hline Magnesium (mg/day) & $283(52)$ & $211(39)$ & $<0.001$ & 0.36 & 0.39 & 0.41 & 61.5 \\
\hline Potassium (mg/day) & $2731(509)$ & $2124(462)$ & $<0.001$ & 0.32 & 0.48 & 0.51 & 63.5 \\
\hline Sodium (mg/day) & $2779(504)$ & $2210(511)$ & $<0.001$ & 0.25 & 0.29 & 0.32 & 57.7 \\
\hline Zinc (mg/day) & $9.9(2)$ & $8.1(1.8)$ & $<0.001$ & 0.39 & 0.29 & 0.31 & 62.8 \\
\hline Iodine $(\mu \mathrm{g} /$ day $)$ & $191(48)$ & $80(44)$ & $<0.001$ & 0.14 & 0.19 & 0.20 & 57.8 \\
\hline \multicolumn{4}{|l|}{ Average of correlation coefficients } & 0.31 & 0.34 & 0.39 & 61.4 \\
\hline
\end{tabular}

${ }^{1}$ FFQav: Average of FFQ1 and FFQ2; ${ }^{2}$ 24hDRav: average of the three $24 \mathrm{hDRs} ;{ }^{3} p$-value from paired $t$-tests; ${ }^{4} \mathrm{r}$ : coefficient correlations after nutrient intakes were log-transformed; ${ }^{5} \mathrm{r}$ adj: correlation coefficient using energy-adjusted nutrient intakes; ${ }^{6} \mathrm{r}$ de-att: de-attenuated correlation coefficients after nutrient intakes were log-transformed and energy-adjusted; ${ }^{7}$ percentage of children classified into the same or an adjacent quintile; the correlations coefficients had a $p$-value $<0.01$ when $r \geq 0.20$, and a $p$-value $<0.05$ when $0.15 \leq r \leq 0.19$.

Figure 2 shows the Bland-Altman plots separately for several nutrients (energy, total fat, trans fatty acids, and iodine). When we examined the Bland-Altman plots to explore the validity of the FFQ, the discrepancies between the two dietary assessment methods were equally likely in either direction. The exceptions were trans fatty acids and iodine intake, for which the difference in absolute intakes increased with increasing average intake, with the mean of FFQ producing systematically higher estimates than the average of three $24 \mathrm{hDRs}$.

Table 6 shows the mean daily vitamin intakes and Pearson coefficient correlations of the biochemical validity from the first FFQ and vitamins biomarkers. The average of correlation coefficients for carotenoids was 0.21 , ranging from 0.06 (lutein and zeaxanthin) to 0.38 ( $\beta$-cryptoxanthin). Low correlation coefficients were observed for other vitamins such as vitamin $\mathrm{E}(r=0.05)$, retinol $(r=-0.09)$ and vitamin $\mathrm{D}(r=0.06)$. When we used the total energy-adjusted intake, the correlations increased slightly for most nutrients, except for lutein and zeaxanthin $(r=0.04) \beta$-cryptoxanthin $(r=0.38)$ and $\alpha$-carotene $(r=0.23)$. In addition, when we compared the estimates from FFQ and biomarkers, the average of percentage of agreement of carotenoids was $59.0 \%$. The correlation coefficient between the intake of fruit and vegetables, the main source of carotenoids intake, and carotenoids biomarkers was $r=0.19$ and the percentage of agreement of both assessment instruments was $60.9 \%$. 
(a)

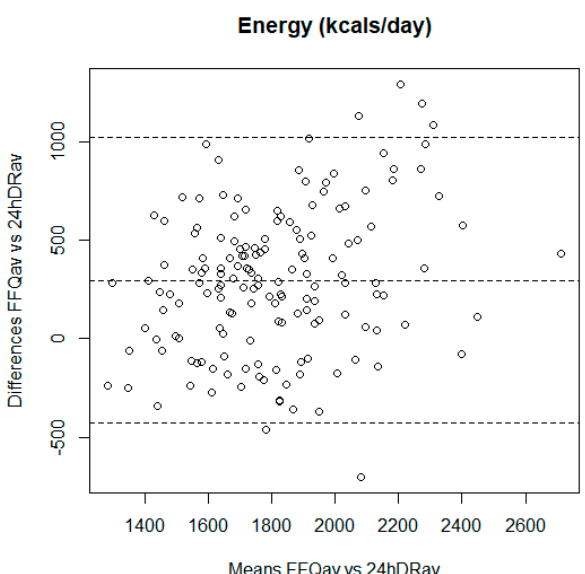

(c)

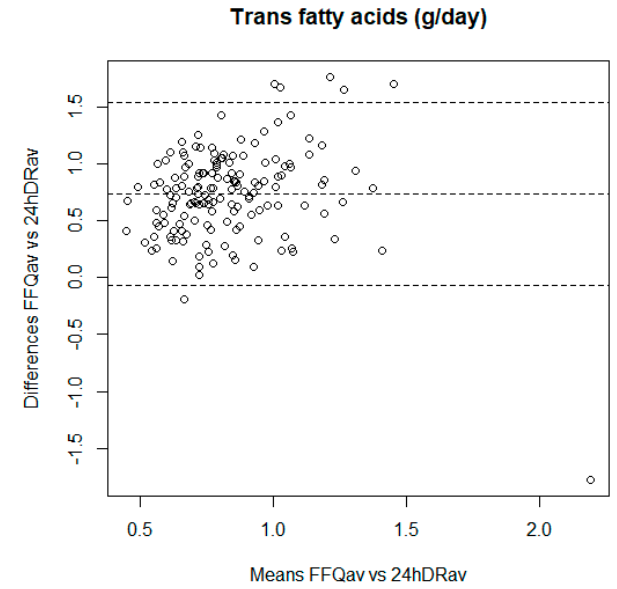

(b)

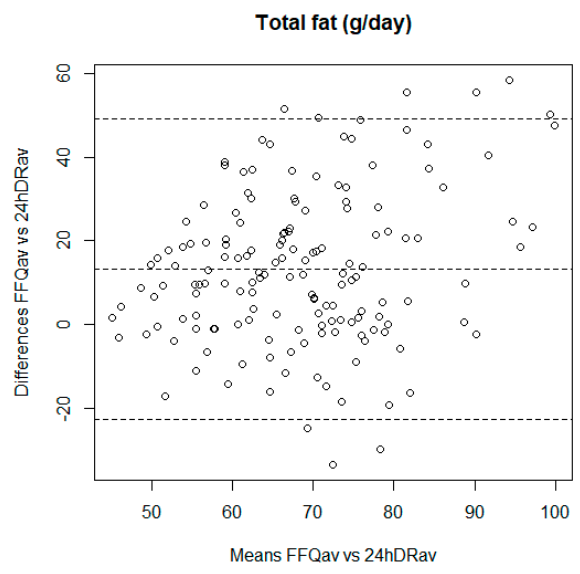

(d)

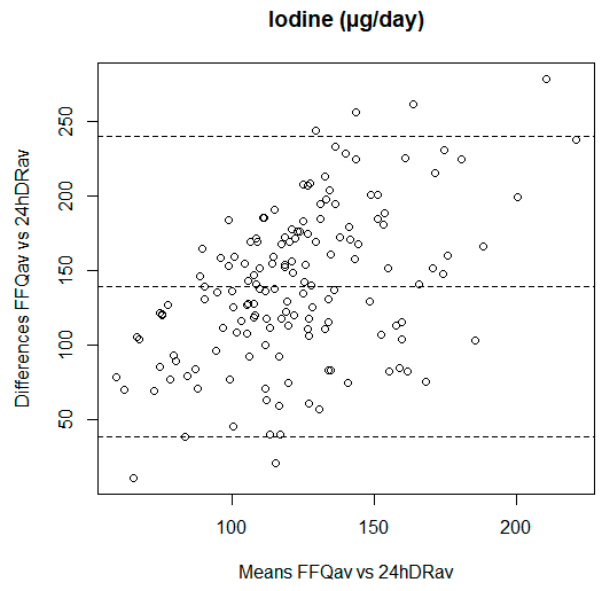

Figure 2. Bland-Altman plots showing the relationship between mean and differences in the daily intake of (a) energy; (b) total fat; (c) trans fatty acids, and (d) iodine estimated with the mean of two FFQ and three 24hDRs.

Table 6. Mean daily vitamin intakes Pearson correlation coefficients from the first FFQ and vitamin biomarkers in children aged 7-9 years of the INMA-Valencia study $(n=156)$.

\begin{tabular}{|c|c|c|c|c|c|}
\hline \multirow[t]{2}{*}{ Nutrients } & \multirow{2}{*}{$\begin{array}{c}\text { FFQ1 }^{1} \\
\text { Mean (SD) }\end{array}$} & \multirow{2}{*}{$\begin{array}{c}\text { Vitamin Biomarkers } \\
\text { Mean (SD) }\end{array}$} & \multicolumn{2}{|c|}{$\begin{array}{l}\text { Pearson Coefficient Correlations between } \\
\text { FFQ1 and Plasma Concentrations }\end{array}$} & \multirow[t]{2}{*}{ Agreement (\%) } \\
\hline & & & $r^{2}$ & $\mathrm{radj}^{3}$ & \\
\hline Vitamin E & $7.6(2.3)$ & 961 (173) & 0.05 & 0.10 & 56.4 \\
\hline Vitamin D & $4.4(1.6)$ & $66(20)$ & 0.06 & 0.11 & 53.2 \\
\hline Retinol & $452(216)$ & $25(6)$ & -0.09 & 0.05 & 51.9 \\
\hline \multicolumn{6}{|l|}{ Carotenoids } \\
\hline Lutein + Zeaxanthin & $1451(780)$ & $13.6(6.3)$ & 0.06 & 0.04 & 50.0 \\
\hline$\beta$ - Cryptoxanthin & $159(102)$ & $14(12)$ & 0.38 & 0.38 & 65.4 \\
\hline Lycopene & $2800(1355)$ & $28(11)$ & 0.24 & 0.26 & 62.8 \\
\hline$\alpha$-Carotene & $816(647)$ & $7.6(4.7)$ & 0.23 & 0.23 & 55.1 \\
\hline$\beta$-Carotene & $2721(2038)$ & $24(16)$ & 0.13 & 0.15 & 56.4 \\
\hline \multicolumn{2}{|c|}{ Average of correlation coefficients } & & 0.21 & 0.21 & 59.0 \\
\hline $\begin{array}{l}\text { Fruits and vegetables vs. } \\
\text { total carotenoids }\end{array}$ & $140(153)$ & $88(34)$ & 0.19 & 0.19 & 60.9 \\
\hline
\end{tabular}

${ }^{1}$ FFQ was firstly administered at baseline (FFQ1); ${ }^{2} \mathrm{r}$ : coefficient correlations after nutrient intakes were $\log$-transformed and cholesterol adjusted for carotenoids and vitamin $\mathrm{E} ;{ }^{3} \mathrm{r}$ adj: correlation coefficient using energy-adjusted nutrient intakes and cholesterol adjusted for carotenoids and vitamin $\mathrm{E} ;{ }^{4}$ percentage of children classified into the same or an adjacent quintile the correlations coefficients had a $p$-value $<0.01$ when $r \geq 0.20$, a $p$-value $<0.05$ when $0.15 \leq r \leq 0.19$, and a $p$-value $>0.05$ when $r<0.15$. 


\section{Discussion}

This validation study supports the argument that the FFQ may be an acceptable method for dietary assessment in Spanish children aged 7 to 9 years. Our results suggest that the FFQ was moderately reproducible for most nutrients and food group intakes, with correlations ranging from 0.25 to 0.70 . The FFQ also showed a reasonable relative validity for most nutrient intakes in comparison to three 24hDRs, and plasma concentration (carotenoids, vitamin E and D), since correlations were in general higher than 0.20 for most of the nutrients.

Regarding the correlation coefficients to assess the reproducibility of the FFQ for nutrients intakes after 9-12 months' period, they were consistent with that reported in previous studies conducted in children with similar ages and using shorter periods of time $[17,26,36,37]$. The results of fruit and vegetable intake reported in our study are similar to those of another study conducted in children living in the Mediterranean area [38]. A previous study conducted with 111 Lebanese children aged 5-10 years reported a higher average of correlation coefficients than observed in our study, $0.62 \mathrm{vs.}$ 0.41 [14], although the better reproducibility could be related to the shorter period of time used between the administration of the two FFQs (one month). Moreover, the number of studies exploring the reproducibility for food groups is very limited [20,37,38]. Field et al. observed coefficients of 0.28 for vegetables and of 0.29 for fruit and vegetables intake [37], considerably lower than those observed in our study ( $r=0.60$ for vegetables, and $r=0.67$ for fruits). However, Buch-Andersen et al. [39] ( $r=0.30$ to 0.84$)$ and Saeedi et al [20] ( $r=0.40$ to 0.82$)$ reported higher correlations than those observed in our study which may be related to the shorter period of time elapse to complete the two FFQ ( 2 or 4 weeks), much lower than the 9-12 months' period used in our study. According to Cade et al. [40] and Willett [25], the range of reproducibility correlation coefficients for nutrient and food groups observed in our study may be considered as adequate, and would suggest that our FFQ is a satisfactorily reproducible tool to assess the nutrient and food intake in Spanish children aged 7-9.

Dietary record has been proposed as a "gold standard" method to validate other dietary assessment methods such as FFQs [3], although they require a high level of motivation and collaboration from participants. Thus, they may become too burdensome and generate losses to follow-up among other problems (e.g., changes in usual diet). In the present study, we considered it more feasible to use a combination of methods, multiple $24 \mathrm{hDRs}$ and biomarkers (for specific nutrients), similar to a previous validation study we performed in children aged 4-5 years from the same project [24]. In accordance with other studies in children with similar age range $[13,19]$, we used three non-consecutive $24 \mathrm{hDRs}$ as the reference method to validate our FFQ, which has been considered adequate to estimate energy and nutrient intakes [41]. We did not use a higher number of $24 \mathrm{hDRs}$ because this could increase the losses of follow-up and because of the limited resources. In addition, it should be noted that a higher number of recalls can decrease the quality of information collected due to a training effect or the weariness of participants [41]. The mean nutrient intake estimated by $24 \mathrm{hDRs}$ observed in our study were around $15 \%-25 \%$ lower than the estimated by the FFQ. Lower estimates for nutrient intakes have been also reported in other studies when comparing $24 \mathrm{hDR}$ and FFQ $[13,14,16,22,26]$. A possible explanation for this lower estimation could be that caregivers did not report the whole children's food intake, particularly for foods eaten out-of-home, since $62.4 \%$ of children in our study reported to use the school lunchroom once a week at least. Despite these disparities in absolute intakes between $24 \mathrm{hDR}$ and FFQ, the average correlation coefficients did not change when children attending school lunchroom were excluded from the analysis, which may suggest that the FFQ can be appropriate for ranking participants' intakes.

The range for correlation coefficients between $24 \mathrm{hDR}$ and FFQ observed for crude nutrient estimates in our study ( 0.14 to 0.48 ) was similar to those reported by Watson et al. [26] (0.17 to 0.46), Scaglius et al. [22] (-0.04 to 0.59) and Moghames et al. [16] (0.26 to 0.54), and lower than the observed by del Pino et al [13] (0.18 to 0.74). When energy-adjusted nutrient intakes were used, the correlation coefficients tended to increase although not substantially, which may be in part due to the wide variability of the study population characteristics since our study was population-based [34]. Similar 
findings have been also reported for energy-adjusted correlation coefficients in other studies [16,22,26]. Finally, the use of de-attenuated correlations further increased correlations due to correction of the day to day variation in nutrient intakes

The Bland-Altman diagrams showed no evidence of bias for any of the 31 nutrients examined, except for TFA and iodine, where there was some evidence that the FFQ overestimated intake compared with the $24 \mathrm{hDR}$ and that this overestimation increased with increasing average intake. The Bland-Altman diagrams only allow a graphical interpretation and the results should be considered together with other results (e.g., correlation coefficients, cross-classification into quantiles). Thus, our study shows a satisfactory level of agreement in intake ranking between the two dietary methods used.

Several validation studies have reported correlation coefficients between FFQ and serum carotenoids in children to additionally support the biochemical validity (calibration) of the FFQ. In one study carried out in 97 children aged 6-10 years [42], the correlations reported between fruit and vegetables intakes and total serum carotenoids were higher than observed in our study $(r=0.30$ vs. $r=0.19)$, although correlations with specific plasma carotenoids were not performed presented. Our results are comparable to other studies conducted in children $[43,44]$ reporting correlations of plasma concentration for $\alpha$-carotene $(r=0.25$ and 0.27 vs. 0.23$), \beta$-carotene (0.14 vs. 0.13$)$ and $\beta$-cryptoxanthin ( 0.36 vs. 0.38$)$. In addition, our results for $\alpha$-carotene, $\beta$-carotene and $\beta$-cryptoxanthin were similar to other study populations [24,30,31]. However, we found lower correlations between dietary intake and serum lycopene than the reported in other studies in children with similar range of age $[43,44]$. The low correlation observed in our study between the intake and serum concentration of lutein and zeaxanthin has been also reported in previous studies [24,43], probably suggesting that food sources of these carotenoids were not commonly consumed by children and a much large sample would be required to study this association or that the plasma level for this nutrient is not very sensitive to the intake in children at this age range. Burrows et al. reported strong correlations between dietary and serum carotenoids after adjusting for BMI; however, the correlations did not materially change when we adjusted for BMI [43]. In our study, we also observed very low correlations between dietary and serum for retinol, vitamin $\mathrm{D}$ and $\mathrm{E}$ which may be due to other non-dietary factors affecting circulation concentrations, efficiency of absorption and metabolism. In fact, retinol concentration is highly regulated by liver stores over a wide range of dietary intakes that can affect serum levels. Also, it has been suggested that plasma concentrations of $\alpha$-tocopherol may not be a good marker of vitamin $\mathrm{E}$ for usually intake in children, and $25 \mathrm{OHD}$ may be a poor biomarker of dietary vitamin $\mathrm{D}$ since the absorption can be influenced for the sunlight exposure $[45,46]$.

A major strength of the present study may be the use of two reference methods (three $24 \mathrm{hDRs}$ and biomarkers) with different error sources to validate the FFQ. Another strength was the use of well-trained nutritionists to collect dietary information during the study period and standard protocols for collecting blood samples. Moreover, the study population was a subsample of the children with very similar characteristics to the whole participant children in the INMA study, a population-based birth cohort and, therefore, the results could be more generalizable to children of the same age range. On the other hand, a potential limitation would be that the dietary information collected by FFQs was self-reported by caregivers and they may be not fully aware of all the food items eaten by their children, especially foods eaten out-of-home. However, we observed that correlations did not change when we excluded the children who had school meals. In addition, the majority of the caregivers in this study had already participated in a prior validation study of a similar FFQ for dietary assessment at the age of 4-5 years and, therefore, they could provide more precise information in this new study. Children were present at the moment of interview and were able to provide additional details about the menu of school lunchroom and other foods and beverages eaten out-of-home. In order to minimize the possible influence of the nutritionists in the dietary report of caregivers, they were instructed in particular to collect the dietary information of the first and second FFQs avoiding subjective opinions. 
In addition, the $24 \mathrm{hDRs}$ were completed by telephone following the USDA Automated Multiple-Pass Method to minimize the forgotten food and beverages consumed by the children in the previous day.

\section{Conclusions}

In conclusion, this study shows that this short FFQ covering a wide range of foods and nutrients may be a useful instrument to evaluate dietary intake for most nutrients and food groups in Spanish children aged 7 to 9 years. The questionnaire showed acceptable reproducibility and validity, comparable to other validation studies with children of similar age range.

Author Contributions: Conceptualization, J.V., M.G.-d.-1.-H. and E.-M.N.-M.; Data curation, M.G.-d.-1.-H., S.G.-P., L.T.-C., L.N.-B., A.O.-C., R.S.-B., M.L. and A.B.; Formal analysis, J.V. and E.-M.N.-M.; Funding acquisition, J.V. and E.-M.N.-M.; Methodology, M.G.-d.-1.-H., S.G.-P., L.T.-C., L.N.-B., R.S.-B., M.L. and A.B.; Validation, M.G.-d.-l.-H., S.G.-P., L.T.-C., L.N.-B. and A.O.-C.; Writing-original draft, J.V. and E.-M.N.-M.; Writing-review and editing, M.G.-d.-1.-H., S.G.-P., L.T.-C., L.N.-B., A.O.-C., R.S.-B., M.L. and A.B.

Funding: This study was funded by grants from Institute of Health Carlos III and Spanish Ministry of Health (Red INMA G03/176; CB06/02/0041; FIS 97/0588; 00/0021-2, PI061756; PS0901958; FIS-FEDER 03/1615, 04/1509, 04/1112, 04/1931, 05/1079, 05/1052, 06/1213, 07/0314; 09/02647; FIS-PI041436, FIS- PI081151, FIS-PI06/0867; FIS-PS09/00090, FIS-PI042018, FIS-PI09 02311, FIS PI11/01007, FISPI13/02429, FISPI16/1288, FISPI17/00260), Fundació la Marato TV3 (201622 10), and Miguel Servet-FEDER CP15/0025. Laura Torres Collado is recipient of a fellowship “Formación de Profesorado Universitario (FPU)" from the Ministry of Education in Spain (FPU14/00046).

Acknowledgments: We would like to appreciate the English revision made by Mr. Jonathan Whitehead and Fernando Granados to assistant in the determination of vitamins. The authors would like to acknowledge all the study participants for their generous collaboration and the interviewers for their assistance in contacting the families and administering the questionnaires. A full roster of the INMA Project Investigators can be found at http://www.proyectoinma.org/presentacioninma/listado-investigadores/en_listado-investigadores.html.

Conflicts of Interest: The authors declare no conflict of interest and the funders had no role in the design of the study; in the collection, analyses, or interpretation of data; in the writing of the manuscript; or in the decision to publish the results.

\section{References}

1. Langley-Evans, S.C. Nutrition in early life and the programming of adult disease: A review. J. Hum. Nutr. Diet. Off. J. Br. Diet. Assoc. 2015, 28 (Suppl. 1), 1-14. [CrossRef]

2. Koletzko, B.; Brands, B.; Grote, V.; Kirchberg, F.F.; Prell, C.; Rzehak, P.; Uhl, O.; Weber, M. Early Nutrition Programming Project Long-Term Health Impact of Early Nutrition: The Power of Programming. Ann. Nutr. Metab. 2017, 70, 161-169. [CrossRef]

3. Willett, W.C. Nutritional Epidemiology, 3rd ed.; Oxford University Press: New York, NY, USA, 2012.

4. Henríquez-Sánchez, P.; Sánchez-Villegas, A.; Doreste-Alonso, J.; Ortiz-Andrellucchi, A.; Pfrimer, K.; Serra-Majem, L. Dietary assessment methods for micronutrient intake: A systematic review on vitamins. $\mathrm{Br}$. J. Nutr. 2009, 102 (Suppl. 1), S10-S37. [CrossRef] [PubMed]

5. Øverby, N.C.; Serra-Majem, L.; Andersen, L.F. Dietary assessment methods on n-3 fatty acid intake: A systematic review. Br. J. Nutr. 2009, 102 (Suppl. 1), S56-S63. [CrossRef]

6. Serra-Majem, L.; Pfrimer, K.; Doreste-Alonso, J.; Ribas-Barba, L.; Sánchez-Villegas, A.; Ortiz-Andrellucchi, A.; Henríquez-Sánchez, P. Dietary assessment methods for intakes of iron, calcium, selenium, zinc and iodine. Br. J. Nutr. 2009, 102 (Suppl. 1), S38-S55. [CrossRef] [PubMed]

7. Ortiz-Andrellucchi, A.; Doreste-Alonso, J.; Henríquez-Sánchez, P.; Cetin, I.; Serra-Majem, L. Dietary assessment methods for micronutrient intake in pregnant women: A systematic review. Br. J. Nutr. 2009, 102 (Suppl. 1), S64-S86. [CrossRef] [PubMed]

8. Lovell, A.; Bulloch, R.; Wall, C.R.; Grant, C.C. Quality of food-frequency questionnaire validation studies in the dietary assessment of children aged 12 to 36 months: A systematic literature review. J. Nutr. Sci. 2017, 6, e16. [CrossRef]

9. Ortiz-Andrellucchi, A.; Henríquez-Sánchez, P.; Sánchez-Villegas, A.; Peña-Quintana, L.; Mendez, M.; Serra-Majem, L. Dietary assessment methods for micronutrient intake in infants, children and adolescents: A systematic review. Br. J. Nutr. 2009, 102 (Suppl. 1), S87-S117. [CrossRef] 
10. Tabacchi, G.; Filippi, A.R.; Amodio, E.; Jemni, M.; Bianco, A.; Firenze, A.; Mammina, C. A meta-analysis of the validity of FFQ targeted to adolescents. Public Health Nutr. 2016, 19, 1168-1183. [CrossRef]

11. Tabacchi, G.; Amodio, E.; Di Pasquale, M.; Bianco, A.; Jemni, M.; Mammina, C. Validation and reproducibility of dietary assessment methods in adolescents: A systematic literature review. Public Health Nutr. 2014, 17, 2700-2714. [CrossRef]

12. Ortiz-Andrellucchi, A.; Sánchez-Villegas, A.; Doreste-Alonso, J.; de Vries, J.; de Groot, L.; Serra-Majem, L. Dietary assessment methods for micronutrient intake in elderly people: A systematic review. Br. J. Nutr. 2009, 102 (Suppl. 1), S118-S149. [CrossRef] [PubMed]

13. Del Pino, D.L.; Friedman, R. Adaptation and validation of an FFQ for 6-10-year-old children. Public Health Nutr. 2011, 14, 826-834. [CrossRef] [PubMed]

14. Kobayashi, T.; Kamimura, M.; Imai, S.; Toji, C.; Okamoto, N.; Fukui, M.; Date, C. Reproducibility and validity of the food frequency questionnaire for estimating habitual dietary intake in children and adolescents. Nutr. J. 2011, 10, 27. [CrossRef] [PubMed]

15. Matos, S.M.A.; Prado, M.S.; Santos, C.A.; D’Innocenzo, S.; Assis, A.M.O.; Dourado, L.S.; Oliveira, N.S.; Rodrigues, L.C.; Barreto, M.L. Validation of a food frequency questionnaire for children and adolescents aged 4 to 11 years living in Salvador, Bahia. Nutr. Hosp. 2012, 27, 1114-1119. [CrossRef] [PubMed]

16. Moghames, P.; Hammami, N.; Hwalla, N.; Yazbeck, N.; Shoaib, H.; Nasreddine, L.; Naja, F. Validity and reliability of a food frequency questionnaire to estimate dietary intake among Lebanese children. Nutr. J. 2016, 15, 4. [CrossRef] [PubMed]

17. Preston, A.M.; Palacios, C.; Rodríguez, C.A.; Vélez-Rodríguez, R.M. Validation and reproducibility of a semi-quantitative food frequency questionnaire for use in Puerto Rican children. P. R. Health Sci. J. 2011, 30, 58-64. [PubMed]

18. Rahmawaty, S.; Charlton, K.; Lyons-Wall, P.; Meyer, B.J. Development and validation of a food frequency questionnaire to assess omega-3 long chain polyunsaturated fatty acid intake in Australian children aged 9-13 years. J. Hum. Nutr. Diet. Off. J. Br. Diet. Assoc. 2017, 30, 429-438. [CrossRef]

19. Rodriguez, C.A.; Smith, E.R.; Villamor, E.; Zavaleta, N.; Respicio-Torres, G.; Contreras, C.; Perea, S.; Jimenez, J.; Tintaya, K.; Lecca, L.; et al. Development and Validation of a Food Frequency Questionnaire to Estimate Intake among Children and Adolescents in Urban Peru. Nutrients 2017, 9, 1121. [CrossRef]

20. Saeedi, P.; Skeaff, S.A.; Wong, J.E.; Skidmore, P.M.L. Reproducibility and Relative Validity of a Short Food Frequency Questionnaire in 9-10 Year-Old Children. Nutrients 2016, 8, 271. [CrossRef] [PubMed]

21. Sahashi, Y.; Tsuji, M.; Wada, K.; Tamai, Y.; Nakamura, K.; Nagata, C. Validity and reproducibility of food frequency questionnaire in Japanese children aged 6 years. J. Nutr. Sci. Vitaminol. 2011, 57, 372-376. [CrossRef]

22. Scagliusi, F.B.; Garcia, M.T.; Indiani, A.L.C.; Cardoso, M.A. Relative validity of a food-frequency questionnaire developed to assess food intake of schoolchildren living in the Brazilian Western Amazon. Cad. Saude Publica 2011, 27, 2197-2206. [CrossRef]

23. Guxens, M.; Ballester, F.; Espada, M.; Fernández, M.F.; Grimalt, J.O.; Ibarluzea, J.; Olea, N.; Rebagliato, M.; Tardón, A.; Torrent, M.; et al. INMA Project Cohort Profile: The INMA-INfancia y Medio Ambiente-(Environment and Childhood) Project. Int. J. Epidemiol. 2012, 41, 930-940. [CrossRef]

24. Vioque, J.; Gimenez-Monzo, D.; Navarrete-Muñoz, E.M.; Garcia-de-la-Hera, M.; Gonzalez-Palacios, S.; Rebagliato, M.; Ballester, F.; Murcia, M.; Iñiguez, C.; Granado, F. INMA-Valencia Cohort Study Reproducibility and Validity of a Food Frequency Questionnaire Designed to Assess Diet in Children Aged 4-5 Years. PLoS ONE 2016, 11, e0167338. [CrossRef]

25. Willett, W.C.; Sampson, L.; Stampfer, M.J.; Rosner, B.; Bain, C.; Witschi, J.; Hennekens, C.H.; Speizer, F.E. Reproducibility and validity of a semiquantitative food frequency questionnaire. Am. J. Epidemiol. 1985, 122, 51-65. [CrossRef]

26. Watson, J.F.; Collins, C.E.; Sibbritt, D.W.; Dibley, M.J.; Garg, M.L. Reproducibility and comparative validity of a food frequency questionnaire for Australian children and adolescents. Int. J. Behav. Nutr. Phys. Act. 2009, 6, 62. [CrossRef]

27. Palma, I.; Farran, A.; Cantos, D. Tablas de Composición de Alimentos por Medidas Caseras de Consumo Habitual en España; McGraw-Hill Interamerican: Madrid, Spain, 2008. 
28. US Department of Agriculture, Agricultural Research Service. USDA National Nutrient Database for Standard Reference, Release 28. Available online: https:/www.ars.usda.gov/northeast-area/beltsville-md-bhnrc/ beltsville-human-nutrition-research-center/nutrient-data-laboratory/docs/sr28-download-files/ (accessed on 17 January 2018).

29. Moshfegh, A.J.; Rhodes, D.G.; Baer, D.J.; Murayi, T.; Clemens, J.C.; Rumpler, W.V.; Paul, D.R.; Sebastian, R.S.; Kuczynski, K.J.; Ingwersen, L.A.; et al. The US Department of Agriculture Automated Multiple-Pass Method reduces bias in the collection of energy intakes. Am. J. Clin. Nutr. 2008, 88, 324-332. [CrossRef]

30. Vioque, J.; Weinbrenner, T.; Asensio, L.; Castelló, A.; Young, I.S.; Fletcher, A. Plasma concentrations of carotenoids and vitamin $\mathrm{C}$ are better correlated with dietary intake in normal weight than overweight and obese elderly subjects. Br. J. Nutr. 2007, 97, 977-986. [CrossRef]

31. Vioque, J.; Navarrete-Muñoz, E.-M.; Gimenez-Monzó, D.; García-de-la-Hera, M.; Granado, F.; Young, I.S.; Ramón, R.; Ballester, F.; Murcia, M.; Rebagliato, M.; et al. INMA-Valencia Cohort Study Reproducibility and validity of a food frequency questionnaire among pregnant women in a Mediterranean area. Nutr. J. 2013, 12, 26. [CrossRef]

32. Craft, N.E. Carotenoid reversed-phase high-performance liquid chromatography methods: Reference compendium. Methods Enzymol. 1992, 213, 185-205.

33. Granado-Lorencio, F.; Herrero-Barbudo, C.; Blanco-Navarro, I.; Pérez-Sacristán, B. Suitability of ultra-high performance liquid chromatography for the determination of fat-soluble nutritional status (vitamins A, E, D, and individual carotenoids). Anal. Bioanal. Chem. 2010, 397, 1389-1393. [CrossRef]

34. Willett, W.C.; Howe, G.R.; Kushi, L.H. Adjustment for total energy intake in epidemiologic studies. Am. J. Clin. Nutr. 1997, 65, 1220S-1231S; discussion 1229S-1231S. [CrossRef] [PubMed]

35. Bland, J.; Altman, D. Statistical methods for assessing agreement between two methods of clinical measurement. Lancet 1986, 1, 307-310. [CrossRef]

36. Arnold, J.E.; Rohan, T.; Howe, G.; Leblanc, M. Reproducibility and validity of a food-frequency questionnaire designed for use in girls age 7 to 12 years. Ann. Epidemiol. 1995, 5, 369-377. [CrossRef]

37. Field, A.E.; Peterson, K.E.; Gortmaker, S.L.; Cheung, L.; Rockett, H.; Fox, M.K.; Colditz, G.A. Reproducibility and validity of a food frequency questionnaire among fourth to seventh grade inner-city school children: Implications of age and day-to-day variation in dietary intake. Public Health Nutr. 1999, 2, 293-300. [CrossRef] [PubMed]

38. Grosso, G.; Mistretta, A.; Turconi, G.; Cena, H.; Roggi, C.; Galvano, F. Nutrition knowledge and other determinants of food intake and lifestyle habits in children and young adolescents living in a rural area of Sicily, South Italy. Public Health Nutr. 2013, 16, 1827-1836. [CrossRef] [PubMed]

39. Buch-Andersen, T.; Pérez-Cueto, F.J.A.; Toft, U. Relative validity and reproducibility of a parent-administered semi-quantitative FFQ for assessing food intake in Danish children aged 3-9 years. Public Health Nutr. 2016, 19, 1184-1194. [CrossRef] [PubMed]

40. Cade, J.; Thompson, R.; Burley, V.; Warm, D. Development, validation and utilisation of food-frequency questionnaires-A review. Public Health Nutr. 2002, 5, 567-587. [CrossRef] [PubMed]

41. Livingstone, M.B.; Robson, P.J. Measurement of dietary intake in children. Proc. Nutr. Soc. 2000, 59, $279-293$. [CrossRef]

42. Byers, T.; Trieber, F.; Gunter, E.; Coates, R.; Sowell, A.; Leonard, S.; Mokdad, A.; Jewell, S.; Miller, D.; Serdula, M. The accuracy of parental reports of their children's intake of fruits and vegetables: Validation of a food frequency questionnaire with serum levels of carotenoids and vitamins C, A, and E. Epidemiology 1993, 4, 350-355. [CrossRef]

43. Burrows, T.L.; Warren, J.M.; Colyvas, K.; Garg, M.L.; Collins, C.E. Validation of overweight children's fruit and vegetable intake using plasma carotenoids. Obesity 2009, 17, 162-168. [CrossRef]

44. Neuhouser, M.L.; Rock, C.L.; Eldridge, A.L.; Kristal, A.R.; Patterson, R.E.; Cooper, D.A.; Neumark-Sztainer, D.; Cheskin, L.J.; Thornquist, M.D. Serum concentrations of retinol, alpha-tocopherol and the carotenoids are influenced by diet, race and obesity in a sample of healthy adolescents. J. Nutr. 2001, 131, 2184-2191. [CrossRef] 
45. Rodríguez-Dehli, A.C.; Riaño-Galán, I.; Fernández-Somoano, A.; Navarrete-Muñoz, E.M.; Espada, M.; Vioque, J.; Tardón, A. [Hypovitaminosis D and associated factors in 4-year old children in northern Spain]. An. Pediatr. 2017, 86, 188-196. [CrossRef]

46. Willett, W.C.; Stampfer, M.J.; Underwood, B.A.; Speizer, F.E.; Rosner, B.; Hennekens, C.H. Validation of a dietary questionnaire with plasma carotenoid and alpha-tocopherol levels. Am. J. Clin. Nutr. 1983, 38, 631-639. [CrossRef]

(C) 2019 by the authors. Licensee MDPI, Basel, Switzerland. This article is an open access article distributed under the terms and conditions of the Creative Commons Attribution (CC BY) license (http://creativecommons.org/licenses/by/4.0/). 